\title{
THREE PERSISTENT MYTHS IN THE ENVIRONMENTAL DEBATE ${ }^{1}$ Roefie Hueting
}

\begin{abstract}
Throughout the last three decades of working on environmental and resource problems I have encountered three persistent myths: (I) environment conflicts with employment; (2) production must grow to create scope for financing environmental conservation; and (3) although society would like to save the environment, it is too expensive. Testing these three propositions, individually and mutually, leads to the conclusion that as long as they dominate the environmental debate, the world will drift ever further away from environmental sustainability.
\end{abstract}

\section{MYTH 1: ENVIRONMENT CONFLICTS WITH EMPLOYMENT}

The proposition that to preserve the environment we must sacrifice employment is probably the major obstacle standing in the way of a sound environmental policy. This is because the proposition overlooks the simple fact that the possible uses or functions of the environment (including natural resources) are scarce goods which require the use of production factors for their restoration, preservation and substitution. Of these, labour is the most important. For example, in the Netherlands more than $80 \%$ of the Net Domestic Product is labour income (including mixed income-i.e., income of industries that goes to private households). In macroeconomic terms, labour is the dominant cost factor. A given amount of production and consumption requires more labour with environmental conservation than without. The extra labour required is used to maintain scarce environmental functions. ${ }^{2}$

This conclusion can be elucidated as follows.

Human beings ultimately depend on three factors for survival and for the level of consumption that they want to attain:

- the possible uses, or functions, of their physical surroundings, the environment: water, air, soil, plant and animal species, space, and natural resources, including energy resources;

- 'hands and brains' - in other words, labour.

And because the brain steers the hands, it is ultimately human ingenuity that counts;

- time.

Of course, capital is also a production factor. But capital goods are manufactured by labour, using elements of our physical surroundings: the environment. Ultimately, the environment, labour and time are the factors with which humans have to make do in obtaining what they need.

The environmental problem can be conceived as a process involving the steady substitution of time, or working hours, through depletion of the environment. For example, spraying herbicides requires less time than manual weeding. The point made in italics above can therefore be reformulated as follows: given the technology available at a given time, it takes more time, that is working hours, to attain a certain goal without depleting the environment than if the environment is depleted.

There is a continuous exchange between the time spent on work with that on leisure. Working hours are reduced either directly or by longer holidays and part-time work. On the other hand, there is an increase in working hours owing to the participation of women, and all kinds of small jobs on the side. Leisure and working hours can be substituted ${ }^{3}$ once a basic level of self-

\footnotetext{
${ }^{1}$ This is a rewritten version of a press presentation of 'Caring for the Earth. a Strategy for Sustainable Living', Rome, October 1991, (World Conservation Union, United Nations Environment Programme and World Wide Fund for Nature).

${ }^{2}$ Conventional labour productivity, whereby the loss of scarce environmental functions is not taken into account, is therefore declining.

${ }^{3}$ The degree of substitution and its direction obviously depend on preferences. Decisions on this point can usually be made individually.
} 
support has been reached. So the point can again be reformulated as follows: attaining a certain goal requires more labour with environmental conservation than without. ${ }^{4}$

Travel provides a clear example of the exchange between time and the environment, both in production and consumption, and also of the potential for substituting time for work by time for consumption. A newspaper reporter can interview three international 'personalities' a week by travelling by airplane, and perhaps one by taking the boat or train. The same holds true for consumption: we can reach more distant places if we travel in ways that burden the environment than if we do so in environmentally friendly ways.

As a society, ${ }^{5}$ we have the following three choices:

- First choice: From this day on we take the train to a nearby resort, instead of taking a plane halfway round the world to Bali. This means a lower level of welfare acquired from goods produced, because the new consumption pattern differs from revealed preferences. It also means a lower real national income, because activities with a capacity for producing a volume of goods that has increased to fabulous heights in recent decades are replaced by activities for which this capacity has increased only modestly, or not at all (see next section).

- Second choice: We continue going to Bali, but we do so by train and boat. This means an increase in travel time, less time for work and consequently lower consumption. A lower volume of national income accrues due both to the lower labour productivity of the transporters and to shorter working hours for the traveller.

- Third choice: We continue flying to Bali and accept the inherent loss of the environment.

With the current state of technology it is impossible to realize existing levels of production and consumption sustainably. ${ }^{6}$ As long as this is the case, we can only increase our production and consumption (per time unit) at the expense of the environment (see also next section). The extra labour needed to save the environment is either directly or, on balance, the result of environmental protection.

Clean production and consumption require provisions and adaptations of all kinds. Examples include cleaning industrial or household waste water, integrated pest control in agriculture, sustainable exploitation of forests, and prevention of noise nuisance. Such provisions and adaptations require more labour directly.

In the case of activities that burden the environment being replaced by environmentally less burdensome activities, there is always a positive balance of additional labour and saved labour. Besides travel (see above) packing is a clear example. Disposable packaging and cutlery were introduced to reduce labour input in order to increase labour productivity. However, the ensuing loss of scarce environmental functions is not taken into account in the calculation of this productivity. If we buy eggs in a basket, milk in a jug and take-away Indonesian food in a rantang, we will certainly cause some loss of employment in the packaging industry, but at the same time we create many more jobs in the service sector. This too results in a decrease in labour productivity: the same goal is reached with more working hours and more consumer time. In the past, the price mechanism forced out labour at the expense of the environment because the environment falls outside this mechanism. This labour will be drawn in again when we start taking the environment into account in whatever form by 'internalising' it (again, given the available technology).

The absurdity of a perceived conflict between the environment and employment becomes particularly evident when we trace its consequences. If conservation of the environment were to be achieved at the expense of employment, then 'clean' production and consumption should

\footnotetext{
${ }^{4}$ Whatever goal, whether travelling or producing meat.

${ }^{5}$ Environmental functions are collective goods. Individual decisions are subject to the prisoner's dilemma. Within a given structure, one puts oneself at great disadvantage while the desired effect is estimated to be negligibly small because one doubts whether others will join the effort. This is why a choice can only be made collectively.

${ }^{6}$ This appears from the study on sustainable national income, carried out by Statistics Netherlands (not yet published).
} 
require less time than 'dirty' production and consumption. Because labour is the dominant cost factor, as explained above, clean production would then be cheaper. From this it follows that there would then be no environmental problem! Everyone would then switch to these cleaner, cheaper production methods, forced to do so by the market. Thus, if merely one company were to switch to clean production, the rest would have to follow suit in order not to be priced out of the market.

The situation is presented upside down: the opposite of what we are being told is true. There is an environmental problem because clean production creates structurally more employment than dirty production. This makes clean products more expensive, and this is why we produce and consume in a way that burdens the environment. ${ }^{7}$

The environment is a collective good, and decisions about it can only be made collectively. If one company switches to production methods that meet national or global sustainability standards, while others do not follow suit, then higher costs will price that company out of the market, and disemploy its employees. Therefore, the logical conditions under which regaining the availability of environmental functions that have become scarce goods creates rather than destroys employment must be made binding for the whole economy. Of the necessary preconditions the following are the most obvious:

1. Income has to be reduced in proportion to the costs of the measures required to conserve the environment. This precondition is completely logical. The extra labour required to restore and conserve scarce environmental functions is deployed to acquire non-market goods. Since income is nothing but a claim to produced goods (the sum of incomes equals the sum of goods produced), environmental measures come down to a reduction of (the growth of) the wage base. This outcome corresponds with an extremely simple datum. A good is scarce if one needs to sacrifice something else that one would like to have in order to acquire it. With scarce goods it therefore holds that more of the one entails less of the other. Thus, ceteris paribus (including the technology available at a given moment), more environment means less production and vice versa. The conflict is therefore apparently between the environment and production or its growth, rather than between the environment and employment.

2. Other countries must take similar measures to the same degree. This precondition is logical too, because otherwise firms from countries without protection measures can compete domestic industries out of the market.

It is difficult if not impossible to test the effects of the introduction of these conditions empirically. The environmental measures taken to date are marginal in relation to what has to be done to arrive at a sustainable use of the environment. Most measures only slow down the rate of deterioration, owing to the persistent and cumulative character of the burden. No government in the world accepts the unavoidable truth that, given the available technology, more environment means less production (and vice versa); so nowhere is reducing the wage rate taken in consideration.

However, the introduction of the necessary preconditions can be simulated and their effects can be tested with the aid of an econometric model. This has been done in the CE-scenario (Potma et al., 1983). A summary in English is given in Hueting (1987). In this study two contrasting scenarios are elaborated, one with business as usual and one giving top priority to saving the environment and resources. All variables that are not relevant to the problem are kept the same. In this way the effects of environmental protection on employment and production are isolated. In the environment scenario, wages are reduced in proportion to the costs of the measures taken, but similar measures in other countries are not assumed. Still, the outcome of this model study confirms what can be expected on the grounds of simple analysis:

\footnotetext{
${ }^{7}$ The point is whether or not we want to 'pay' for environmental conservation in the form of re-allocating production factors for the implementation of technical provisions or in the form of a direct shift from environmentally burdening to environmentally friendly activities. Examples: from car to bicycle, from a lot of meat to a little meat plus beans. There is no way to establish unambiguously what sacrifices we are prepared to make to preserve the environment (see Epilogue).
} 
unemployment decreases ${ }^{8}$ and production growth is checked (if the outcome of a model is not in conformity with the underlying theory, one of the two has to be reconsidered).

One of the underlying assumptions of the model study is that the demand for goods and services produced remains fully intact. For example, people have been travelling from time immemorial; they will not stay at home if car and air traffic decreases; they will go by train, boat or bicycle, even though they do not get as far per unit of time; the revealed preference for travel will not suddenly disappear.

The enormous concern voiced by governments and industry about environmental issues would lead one to expect major encouragement of research on the logical conditions under which two major issues of our time - unemployment and the environment-neutralize rather than reinforce one another. But nothing could be further from the truth. The above-mentioned CEscenario has been completely ignored.

Openly admitting the above obvious fact and creating the logical conditions under which the problems of unemployment and the environment neutralize one another would lead to a structural drop in labour productivity. This certainly checks the growth of production as measured in national income, and probably leads to a lower production level. With this conclusion we have now arrived at the heart of the environmental problem - growth of production.

\section{MYTH 2: PRODUCTION MUST GROW TO SAVE THE ENVIRONMENT}

Growth is at the heart of the environmental problem. Humans depend on the possible uses, or functions, of the environment for all their activities. Production growth, as measured in terms of national income, increasingly impairs environmental functions, including those that make life on this planet possible. This process whereby the most fundamental scarce and consequently economic goods available to humans are destroyed, is generally called 'economic growth' and is identified with economic success. Growth defined in this manner receives top priority in every country of the world.

The identification of production growth with economic growth and economic success suggests that things go well economically only when production grows. This, however, completely contradicts economic theory. Economic theory by no means assumes that humans try to attain the highest possible production. Rather, it assumes that humans, in their dealings with scarce goods, try to attain the highest possible level of satisfaction of wants - in other words, welfare. In doing so, it is certainly not only goods and services produced for the market that are involved. The concepts 'production', 'money', and 'market' are absent in the definition of the subject matter of economics (cf., Hennipman, 1962, 1995; Robbins, 1952).

It follows that we can only speak of economic growth and economic success if there is an increase in satisfaction of our wants - that is, in our welfare. Welfare depends on many more factors than only production, and one of these is surely the environment. If, at the margin, we value the environment higher than production, and measures to preserve the environment lead to a lower level of production, then less production leads to greater welfare.

The identification of an increase in national income with economic growth and economic success masks economic development and perverts economic theory. National income measures the volume of production. An increase in national income, therefore, is an increase in production. The question then arises why years of pleading to call things by their proper names have led nowhere. Is it because the Western credo of progress has become ever more linked to production growth? If this is the case, then we are up against a deep-rooted, erroneous notion of progress that is threatening our planet.

The all-time low in reflections on the relationship between growth and the environment is the widespread proposition that production must increase in order to create scope for financing environmental conservation. There are two ways of elucidating why this proposition is perhaps the most dangerous ever invented. The first is to examine which activities contribute most to growth. The second is to examine what effects environmental protection has on production levels.

8 Of course, seasonal, frictional and business-cycle unemployment are not influenced, nor the unemployment caused by the fact that labour productivity is lower than the legal minimum wage. 
An analysis of the basic source material of the Dutch National Accounts (NA) (Hueting, 1981; Hueting et al., 1992) ${ }^{9}{ }^{10}$ shows that between one quarter and one third of the activities making up the national income do not contribute to its growth because it is difficult, if not impossible, to measure the development of productivity. These activities include production by the government, such as governing, the administration of justice, and most cultural activities, such as music and theatre. Another part of the activities contributes little to the growth of national income. The desired growth of at least $3 \%$ a year expressed in official policy, which means doubling production every 23 years, must therefore be achieved by much higher growth percentages in the remaining activities. Unfortunately, these are mainly precisely those activities that cause the greatest environmental damage, owing to their use of space, soil and resources, and their pollution, in production or consumption. These activities include the oil and petrochemical industries, agriculture, public utilities, road construction and mining. Roughly $30 \%$ of the activities, precisely the most environmentally damaging, generate about $70 \%$ of production growth.

Moreover, according to Kuznets $(1947,1948)$, some of the activities included in the $70 \%$ are complementary to those included in the $30 \%$. They are basically transaction costs. Kuznets argues that expenditure on these activities is of a cost character and should therefore be entered as intermediate deliveries. Entering them as final deliveries is double counting, according to Kuznets. Examples include the expenditure invoked by the complexity of modem, urban patterns of living, such as expenditure on bridging greater distances between home and work, on banks, employment agencies, unions, brokerage houses and on legislation. Kuznets distinguishes three classes of such activities. A summary is given in Hueting $(1980,1992 a)$.

The first way of testing the proposition 'growth is required to save the environment' yields the following result: the lion's share of the contribution to growth comes from the most damaging activities. We can now test the proposition by looking into the effect of environmental protection on growth.

Environmental conservation is a problem of shifting activities, in other words of re-allocation; it is not a funding problem involving a need to earn extra money to pay for it; macroeconomically, extra money can be earned only by extra production, which generally causes an extra burden on the environment (given the available technology, see above). Re-allocation in order to slow down the depletion of the environment and natural resources can be accomplished in two ways: by prescribing environmental conservation measures for production and consumption activities, and by direct changes in production and consumption patterns.

The first method, prescribing add-on provisions or changes in production processes, leads to real price increases. This is self-evident because extra production factors have to be factored in. A real price increase is identical to a decrease in the growth of national income. Stated simply, you can buy less for the same income. The ensuing check on growth is partially masked because, according to the current conventions of the NA, losses of scarce environmental functions (which are normal economic goods, see Hueting, 1980, 1992b) are not written off, but their restoration is written on, as far as it is financed by the government or private individuals. This is known as 'double counting' or 'asymmetric entering'. The effect can nevertheless be observed because nobody perceives the construction of a sewage treatment plant or the installation of a catalytic converter as an increase in his or her consumption.

Technical measures can often only put a brake on the rate of deterioration because of the persistent and cumulative character of environmental damage. In such cases, the only solution is to supplement technical measures by direct changes in production and consumption patterns. ${ }^{11}$ A direct shift from environmentally burdening to environmentally friendly activities also checks growth, or might lead to a lower production level. This is because the accumulated capacity of the $30 \%$ damaging activities to produce an annual volume of goods (the productivity) has increased

\footnotetext{
${ }^{9}$ van der Ploeg $(1994 a, b)$ implicitly arrives at the same conclusion with his distinction of the industry in a hard sector with a high growth rate in productivity and much pollution, and a soft sector with a low growth rate in productivity and little pollution.

${ }^{10}$ The sectorial composition of the Dutch National Accounts does not differ appreciably from that of the UK nor probably from that of most other Northern countries (see Hueting, 1981).

${ }^{11}$ This appears from the study on sustainable national income, carried out by Statistics Netherlands (not yet published).
} 
gigantically over the past few decades, whereas this capacity has not increased, or only very little, in the more environmentally friendly activities. This is due partly to the fact that the depletion of the environment and of resources is not accounted for under the current conventions of the NA. ${ }^{12}$

Environmental measures lead to a check on growth, and growth apparently usually leads to further environmental deterioration. The widely held notion that 'growth is required to finance environmental conservation' thus proves to be extremely dangerous for the environment.

Safeguarding the environment in the long term requires that we shift our priorities from production growth to environmental conservation, and to wait and see to what extent production may then increase. This avoids the risks for future generations and is much cheaper in the long run: restoration is usually more expensive than preventing environmental loss. Such a shift in priorities would, furthermore, provide much better incentives for research into and application of environmentally friendly technologies than the current policy of focusing on production growth.

The combination of growth and environmental conservation is only possible in the case of technologies being invented that: (1) are sufficiently clean; (2) do not deplete energy stocks and other natural resources; (3) leave the soil intact; (4) leave sufficient space for the survival of plant and animal species; and (5) are no more expensive than currently available technologies. This is scarcely conceivable for the entire spectrum of our activities. At any rate, such technologies are not yet available. Those who argue in favour of both growth and environmental conservation, or even for growth in order to save the environment, are therefore either blind to reality or are gambling on technologies that have neither been invented nor become operational, thus risking the basis of our existence.

\section{MYTH 3: WE WOULD LIKE TO SAVE THE ENVIRONMENT, BUT IT IS TOO EXPENSIVE}

We would love to save the environment, but it is too expensive. Of the three myths this may not be the most dangerous one, but it is certainly the most hypocritical. All fundamental solutions for safeguarding the environment are clearly much cheaper ${ }^{13}$ than continuing the process that is threatening life on this planet.

For example: travelling by bicycle is much cheaper than driving the same distance by car. Heating one room, in combination with a sweater and an extra blanket, is much cheaper than heating the entire house. A vacation by boat or train is cheaper than a holiday flight. A diet combining some meat and beans is cheaper than eating lots of meat. Winter vegetables in winter are cheaper than summer vegetables in winter. Raising two children is cheaper than raising ten.

The burden on the environment is determined by the number of people, the amount of activity per person, and the nature of this activity. Because activities with little or no impact on the environment can be expanded, the shift to environmental sustainability comes down to adapting the number of individuals of our species and the kind of activities we engage in to the carrying capacity of our planet. This adaptation is extraordinarily cheap.

Of course, there is an economic sacrifice to be made; otherwise there would be no environmental problem. Most of us would love to make unrestricted use of the private car, are mad about eating meat, and prefer to have sex without a pill or condom. Recent initiatives to calculate a sustainable level of activities--the sustainable national income (Hueting et al., 1992)will show a major difference with the standard national income. But if we unlink our credo of progress from the growth of our consumption, there is no reason at all to panic. In the first place, shifting to sustainability will not damage our health. On the contrary, environmentally-friendly activities are usually healthier than those that harm the environment. Second, a sustainable level of activity by no means implies a return to the Middle Ages, as often claimed. The global national income is now 4 times higher than it was about 1950. Were living conditions then worse for most of the people in the world than they are today? A sustainable level of activity will probably be

\footnotetext{
${ }^{12}$ The increase in volume, realised in the highly productive, environmentally burdening sectors is spread across society owing to demand and supply and many linking mechanisms. Thus, the volume produced by a hairdresser is not appreciably greater than that of his colleague 40 years ago, whereas his real (deflated) income, or his claim to a volume of produced goods, has risen by a factor of 4 during that same period.

${ }^{13}$ Cheaper in the ordinary everyday meaning of the word - that is, in the sense that less input of production factors is required. See footnote 7 and the text three paragraphs down.
} 
higher than that of 40 years ago. Thus, according to a rough estimate by Tinbergen and Hueting (1991), global production and consumption will have to be halved in order to attain sustainable levels, thus to repay our debt to future generations.

\section{EPILOGUE}

Given a certain availability, the value (and the scarcity) of goods depends on preferences. For market goods, prices indicate their marginal utility relative to one another. Prices say nothing about the value of market goods relative to scarce environmental functions. The value of these functions can never be fully established, because the intensity of the wants for them (relative preferences) can mostly be determined only very partially or not at all. For losses of function that threaten the future, such as the extinction of species, it is impossible to do so (Hueting, 1980, $1992 \mathrm{~b})$. This is why the true value of goods produced and consumed at the expense of the environment is equally unknowable. In the conflict between production and the environment we therefore have to weigh two unknown values - not one known value against one unknown value. In doing so we can make assumptions about the preferences, such as the assumption that the economic subjects want to use the environment sustainably, and use estimated production costs of environmental functions (their elimination costs) and market goods (Hueting et al., 1995). That is not the subject of this paper. Scarce environmental functions - the most fundamental economic goods at the disposal of human beings because they constitute the very basis of our existence-cannot be preserved as long as in any discussion concerning the weighting process the information on the key items - employment, growth and financial feasibility - is turned upside down.

\section{ACKNOWLEDGEMENTS}

The author would like to thank R.J.A. Goodland (The World Bank), P. Bosch (European Environmental Agency), R.J.A. Janssen (Statistics Netherlands), J. Proops (Keele University), and L. van der Geest and T.P. van Walderveen (editors of Economisch Statistische Berichten) for their comments on the earlier version of this paper.

\section{REFERENCES}

Hennipman, P. (1962). Doeleinden en criteria der economische politiek. In: J.E. Andriessen and M.A.G. Meerhaeghe (Editors), Theorie van de Economische Politiek. Stenfert Kroese, Leiden. Hennipman, P., 1995. Welfare Economics and Theory of Economic Policy. Edward Elgar Publishing Company, Brookfield, UK.

Hueting, R., 1980. New Scarcity and Economic Growth. North- Holland, Amsterdam-New YorkOxford.

Hueting, R., 1981. Some comments on the report 'A low energy strategy for the United Kingdom', compiled by Gerald Leach et al. International Institute for Environment and Development (IIED). [Prepared for the Working Party on Integral Energy Scenarios, The Hague, 20 May. Also published as: De relatie tussen produktiegroei en energieverbruik. Maakt groeifanatisme blind? Economisch-Statistische Berichten, 24 June, pp. 609-611.]

Hueting, R., 1987. An economic scenario that gives top priority to saving the environment. Ecol. Model., 38: 123-140.

Hueting, R., 1992a. Calculating a Sustainable National Income: a practical solution for a theoretical dilemma. In: A. Franz and C. Stahmer (Editors), Approaches to Environmental Accounting. Physica-Verlag, Heidelberg.

Hueting, R., 1992b. The economic functions of the environment. In: P. Ekins and M. Max-Neef (Editors), Real-Life Economics. Routledge, London-New York.

Hueting, R., Bosch, P. and de Boer, B., 1992. Methodology tbr the calculation of sustainable national income. Statistical Essays, M 44, Statistics Netherlands, Voorburg. [Also published as WWF International report, Gland, Switzerland.]

Hueting, R, de Boer, B., Bosch, P. and van Soest, J.P., 1995. Estimating sustainable national income. In: W. van Dieren (Editor), Taking Nature into Account. Springer Verlag, New York. 
Kuznets, S., 1947. National income and industrial structure. In: The Econometric Society Meeting, September 6-18, 1947, Washington, DC. Proceedings of the International Statistical Conferences, Vol. V. Calcutta, undated, p. 205.

Kuznets, S., 1948. On the valuation of social income. In: Economica, February/May. Potma, T.G., Becht, H.Y.,

Hueting, R. and Zijlstra, G.J., 1983. Het CE-Scenario. Een realistisch alternatief. Centrum voor Energiebesparing, Delft.

Robbins, L., 1952. An Essay on the Nature and Significance of Economic Science. Macmillan, London.

Tinbergen, J. and Hueting, R., 1991. GNP and market prices: wrong signals for sustainable economic success that mask environmental destruction. In: R. Goodland, H. Daly, S. El Serafy and B. yon Drost (Editors), Environmentally Sustainable Economic Development: Building on Brundtland. United Nations Educational, Scientific and Cultural Organization, Paris. [Also in Goodland, R. et al. (Editors), 1992. Population, Technology and Lifestyle. The Transition to Sustainability. Island Press, Washington, DC; and in R. Goodland et al. (Editors), 1991, Environmentally Sustainable Economic Development: Building on Brundtland.

Environment Working Paper No. 46, The World Bank, Washington DC.]

van der Ploeg, F., 1994a. Zachte sector van economie moet naar markt worden overgeheveld. NRC Handelsblad, 9 April. van der Ploeg, F., 1994b. Scheefgroei in de economie.

Milieuforum, February. 